EPJ Web of Conferences 114, 02041 (2016)

DOI: 10.1051/epjconf/201611402041

(C) Owned by the authors, published by EDP Sciences, 2016

\title{
A combined experimental-numerical approach for two-phase flow boiling in a minichannel
}

\author{
Sylwia Hożejowska ${ }^{1, a}$, Mirosław Grabowski ${ }^{2}$ \\ ${ }^{1}$ Kielce University of Technology, Department of Informatics and Applied Mathematics, Al. 1000-lecia PP 7, 25-314 Kielce Poland \\ ${ }^{2}$ Warsaw University of Technology, Institute of Mechanical Engineering, Plock Campus, ul. Łukasiewicza 17, 09-400 Plock, Poland
}

\begin{abstract}
The paper addresses experimental and numerical modeling of the two-phase flows in an asymmetrically heated horizontal minichannel. Experimental measurements concerned flows of evaporating ethanol in a minichannel with rectangular cross section $1.8 \mathrm{~mm} \times 2 \mathrm{~mm}$. In order to observe the flows, measuring system was designed and built. The system measured and recorded basic heat and flow parameters of flowing fluid, and the temperature of external surface of the heater by using infrared camera and recorded images of flow with high-speed camera. The second aim of the paper was to formulate appropriate flow boiling heat transfer model, which would minimises the use of experimentally determined constants. The procedure of calculating the temperature of the ethanol is coupled with concurrent process of determining the temperature distributions in the isolating foil and the heating surface. The two-dimensional temperature distributions in three subsequent domains were calculated with Trefftz method. Due to the Robin condition, heat transfer coefficient at the heating surface-ethanol interface was calculated based on the known temperature distributions of the foil and liquid. Additionally, the paper describes the relation between two sets of functions used in the calculation. Numerical calculations made by Trefftz method were performed with using experimental data.
\end{abstract}

\section{Introduction}

Progress in miniaturization of modern components and systems, driven by technological advances, has resulted in the development of methods that provide their functionality and proper performance. Reduced energy and material consumption are required for contemporary small-scaled heat exchangers, while maintaining or possibly improving their thermodynamic performance by transferring increased heat fluxes. One way to intensify heat transfer and meet the criteria above is connected with the phase transition of refrigerants, in particular in flow boiling in minichannels. This results in idea of the so-called compact heat exchangers (evaporators and condensers) used within cooling systems. Additionally, due to small internal volumes of the minichannels, their environmental impact shall be limited, because in the case of a leakage, the amount of the refrigerant released to the surroundings will be negligible. The main condition for proper operation of high-efficiency miniature heat exchangers is steady and stable flow. One of the key problems in design process is the selection of proper calculation procedures that will reflect the processes governing the heat transfer in the small-sized channels. The objective of this study is to build appropriate mathematical models describing heat transfer processes and to provide effective solutions for related problems.

\footnotetext{
$\overline{{ }^{a} \text { Corresponding author: ztpsf@tu.kielce.pl }}$
}

Mathematical model building should be based on the experiment that both provides input data and verifies the results. This paper discusses the results of experimental study of flow boiling of ethanol in a horizontal minichannel with $1.8 \mathrm{~mm} \times 2 \mathrm{~mm}$ crosssection. The design of the measurement system was based on the experience gained from earlier works reported by the authors and other researchers $[1,2]$. The paper proposes a mathematical model describing heat transfer in the measurement module for single and twophase flows of ethanol in the minichannel. To determine approximate temperature distributions for the insulating foil, the heater and the ethanol (two-phase flow), the Trefftz method was used. Known temperature distribution on the heating surface and the ethanol allowed determining the heat transfer coefficient in the heater-ethanol contact region. Measurement data from the experiment were used in the calculations.

\section{Experiment}

The investigations were conducted on the experimental setup, figure 1, which allowed:

1. pumping the working liquid through the minichannel at the set volumetric flow rate, inlet temperature and pressure.

2. heating the liquid in the minichannel to the boiling temperature. 
3. measuring the basic thermodynamic and flow parameters: volumetric flow rate of the liquid flowing through the minichannel, temperature at the inlet and outlet, pressure at the inlet, pressure drop along the minichannel length, the power of the electrical current flowing through the heater; recording the temperature distribution on the surface of the insulating foil separating the heater from the ambient, 1.3 in figure 2; recording resulting two-phase flow structures with a video camera.

The main part of the setup, figure 1 , comprises the measurement module with the minichannel 1 . The module is fitted with pressure sensors $(p)$ and temperature sensors $(T)$ with index 1 for the inlet and 2 for the outlet.

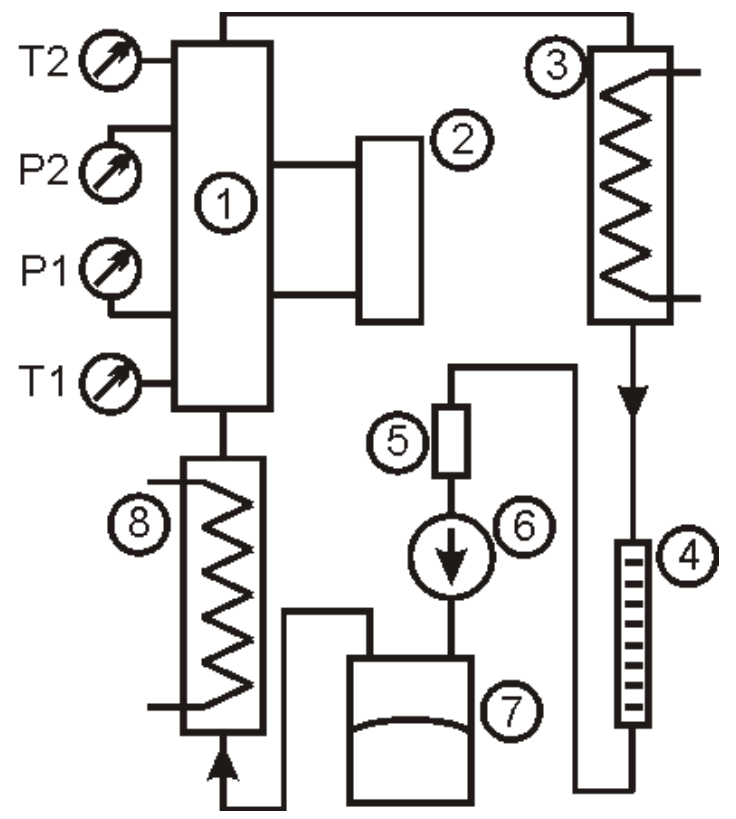

Figure 1. Flow loop: 1 - measurement module with the minichannel, $2-$ DC power supply for the heater, 3 - condenser, 4 - rotameter, 5 - filter, 6 - pump,

7 - pressure control, 8 - preheater.

On one of the minichannel walls, a heater is mounted 1.2 figure 2, which is supplied from the DC power supply 2 figure 1. The boiling fluid leaving the minichannel is directed to the condenser 3 . From the condenser, the fluid flows to the rotameter 4 and further to the filter 5 before it reaches the precision micropump 6. The micropump pumps the fluid to the pressure control, which is an expansion vessel. The fluid is on one side of it and on the other side, the supplied compressed air is used to force appropriate pressure value in the system. From the pressure control the fluid flows to the preheater, where it is preheated to the temperature close to the saturation temperature. The difference between the saturation temperature and that at the minichannel inlet is known as supercooling. Leaving the preheater, the fluid flows into the minichannel, figure 2 . The measurement module is composed of the hub 1.1, in which the minichannel is milled 1.4. A lid with a transparent viewing window closes the minichannel on one side 1.5 , and on the other side there is a heater 1.2 in the form of a flat strip made of Fecral 135 electrical resistance alloy with dimensions $2 \mathrm{~mm} \times 0.1 \mathrm{~mm}$, sealed with the insulating foil 1.3.
Type $\mathrm{K}$ thermocouples with the cross-section of $0.5 \mathrm{~mm}$, and pressure sensors $0-2.5$ bar are mounted in the hub.

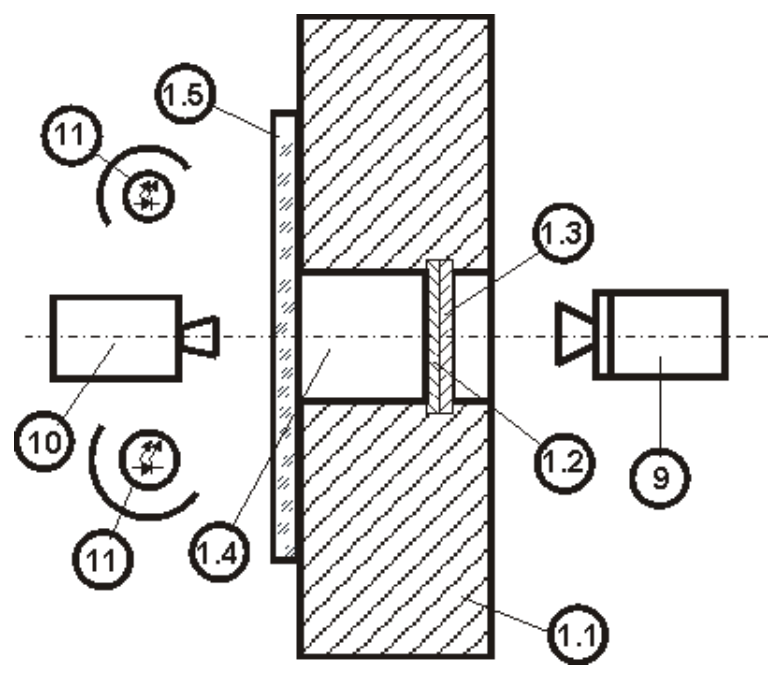

Figure 2. Cross-section of the measurement module with the minichannel and the location of the IR and video cameras and lighting (not to scale): 1.1 - hub, 1.2 - heater, 1.3-insulating foil, 1.4 - minichannel with boiling fluid, 1.5 - glass lid closing the channel, 9 - IR camera, 10 - video camera, 11 - LED lights.

The heater, 1.2 figure 2 , is powered from the programmable high current DC power supply 2 figure 1 , manufactured by TDK Lambda. During heating and phase change, the two-phase structures can be observed and recorded using the fast video camera, 10 figure 2, (Phantom 711 by Vision Research), with a resolution of $1280 \times 800$ pixels at $7530 \mathrm{fps}$. This camera to be efficient requires very intense lighting. Powerful incandescent lamps would heat the channel thus introducing an additional measurement error. To avoid this, LED light $64 \mathrm{~W}$ constructed by the authors were used, 11 figure 2 . The lighting consists of two diode sections LED CLL 010 - 0305 A1 - 273 M1 A2 with 7 diodes in each section arranged along the minichannel length and fitted with additional lenses to disperse light. A section of extra 9 LEDs can be placed on a flexible arm to precisely direct the luminous flux to the selected spot.

The minichannel can be divided into three regions associated with the ways of heat supply. The heat generated by the heater is supplied only to region I, figure 3.

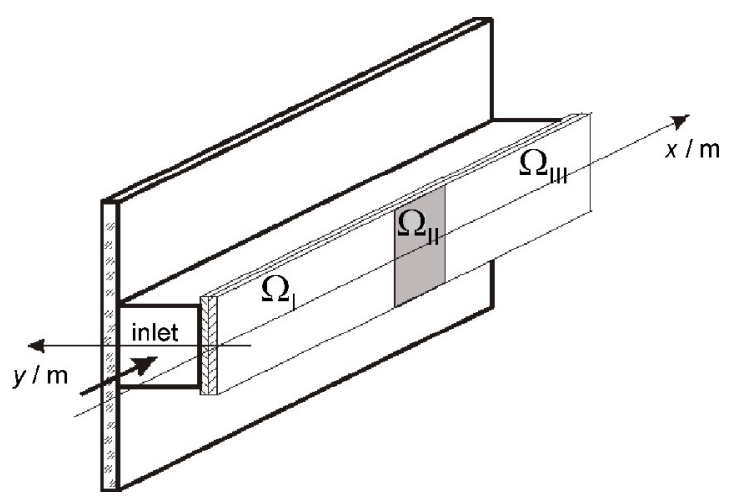

Figure 3. Minichannel division into the heated and the adiabatic parts. 
For reasons related to the design, temperature field on the insulating foil cannot be recorded in region II. In region III, as in the case of region II, the heat is not supplied and all heat and flow parameters are recorded (as in region I). The design of the experimental stand is described more detailed in [3].

\section{Experimental results}

The experiments allowed recording the flow parameters, the heat flux supplied to the heater, the images of the two-phase structures occurring during boiling in the minichannel, figure 4 , and the thermograms with temperature field on the insulating foil.

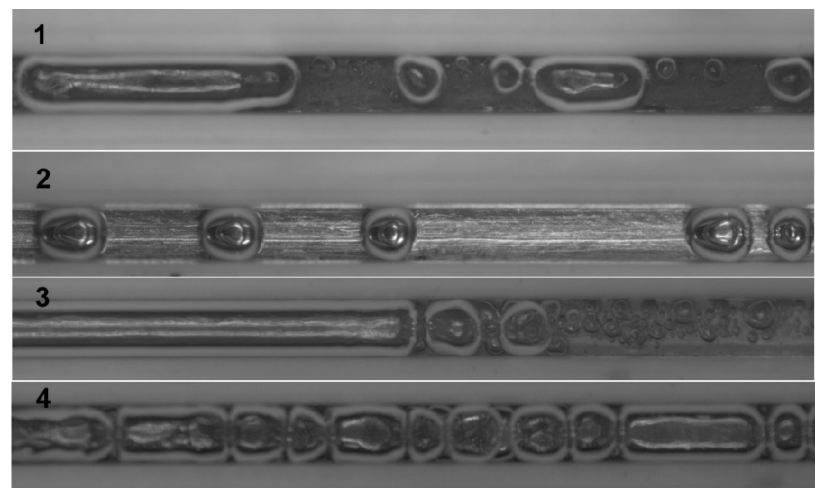

Figure 4. Two-phase flow structures in the flows of the following parameters: 1 - volumetric flow rate $1.41 \mathrm{E}-7 \mathrm{~m}^{3} \mathrm{~s}^{-1}$, heat flux $143.3 \mathrm{kWm}^{-2}$, distance from the minichannel inlet $20 \mathrm{~mm}, 2$ - volumetric flow rate $1.41 \mathrm{E}-7 \mathrm{~m}^{3} \mathrm{~s}^{-1}$, heat flux $120.3 \mathrm{~kW} \mathrm{~m}^{-2}$, distance from the minichannel inlet $150 \mathrm{~mm}$, 3 -volumetric flow rate $5.88 \mathrm{E}-8 \mathrm{~m}^{3} \mathrm{~s}^{-1}$, heat flux $120.3 \mathrm{~kW} \mathrm{~m}^{-2}$, distance from the minichannel inlet $40 \mathrm{~mm}, 4$ - volumetric flow rate $2.1 \mathrm{E}-8 \mathrm{~m}^{3} \mathrm{~s}^{-1}$, heat flux $143.3 \mathrm{~kW} \mathrm{~m}^{-2}$, distance from the minichannel inlet $40 \mathrm{~mm}$

The data above were used to prepare temperature profiles for each measurement instance. Figure 5 shows an example of temperature distribution along the channel length for the flow with the volumetric flow rate of $8.3 \mathrm{E}-8 \mathrm{~m}^{3} \mathrm{~s}^{-1}$ and the heat flux of $153.3 \mathrm{~kW} \mathrm{~m}^{-2}$.

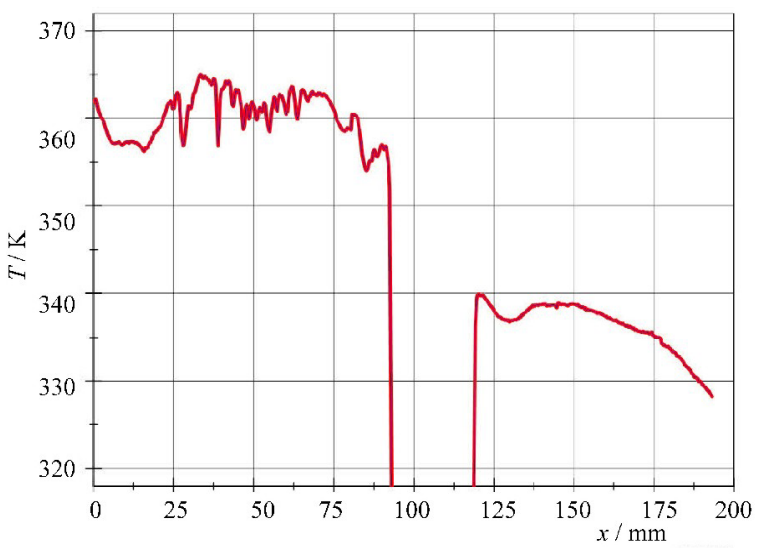

Figure 5. Temperature distribution recorded by the IR camera on the insulating foil for the flow with volumetric flow rate of $8.3 \mathrm{E}-8 \mathrm{~m}^{3} \mathrm{~s}^{-1}$, and the heat flux of $153.3 \mathrm{~kW} \mathrm{~m}$.
The analysis of the photographs obtained using the fast video camera allowed determining the void fraction in the minichannel $\varphi$, defined as a ratio of the surface area of vapor bubbles to the surface area of the channel (projection area on the photo plane). The way to estimate void fraction was presented in [4]. An example of the void fraction along the channel length is shown in figure 6.

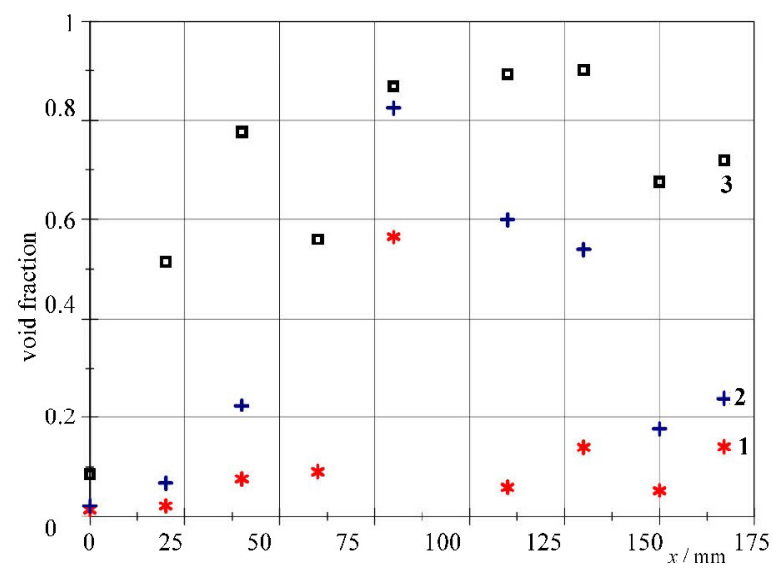

Figure 6. Void fractions relative to the distance from the minichannel inlet for selected thermal and flow parameters: 1 - volumetric flow rate $8.3 \mathrm{E}-8 \mathrm{~m}^{3} \mathrm{~s}^{-1}$, heat flux $100.4 \mathrm{~kW} \mathrm{~m}^{-2}$, 2 - volumetric flow rate $5.1 \mathrm{E}-8 \mathrm{~m}^{3} \mathrm{~s}^{-1}$, heat flux $99.2 \mathrm{~kW} \mathrm{~m}^{-2}$, 3 -volumetric flow rate $2.1 \mathrm{E}-8 \mathrm{~m}^{3} \mathrm{~s}^{-1}$, heat flux $102.6 \mathrm{~kW} \mathrm{~m}^{-2}$.

The rapid void fraction changes seen in the diagram above are associated with the oscillations that occur at higher heat fluxes. The oscillations were characterized by cyclic violent evaporation (high $\varphi$ ) followed by an inflow of the fluid (low $\varphi$ ). Figure 7 illustrates the influence of the volumetric flow rate and the heat flux on the void fraction.

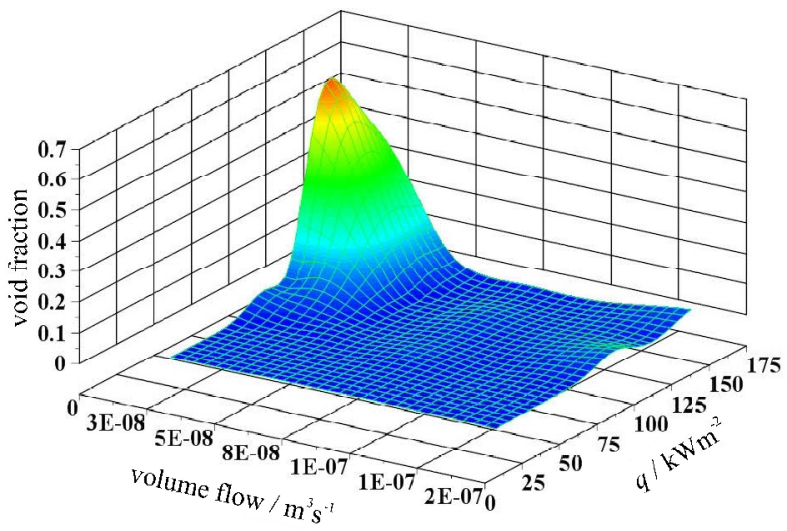

Figure 7. Dependence of the averaged void fraction on the heat flux and the liquid volumetric flow rate.

The measurement data were read and recorded by a control system based on specialized measurement modules manufactured by National Instruments. The basic part of the system is the main module NI cDAQ-9172, in which submodules are mounted for measuring process parameters and control parameters for the pump, light and cameras. To avoid large errors, high accuracy sensors are used in the measurement systems. Some of these sensors, for example, Czaki thermocouples 
cooperating with module NI 9211 were calibrated, which allowed obtaining the limiting temperature measurement error of up $0.55 \mathrm{~K}$. The TDK Lambda adapter internal measurement system was used to measure the amperage and voltage of the current supplied to the heater. The limiting reading error in this was $0.1 \%$ measured value. To estimate the resultant measurement error for the heater output and the volumetric flow rate of the working liquid, the maximum uncertainty method was used. Table 1 shows the values of absolute errors. Error in measuring the void fraction is more difficult to estimate. The measurements are based on a computer graphic analysis of photographs obtained with a high-speed video camera. Graphical methods do not provide high accuracy, especially for cases with significant dispersion of vapour bubbles and their irregular pattern. These reasons result in difficulties to identify the interfacial boundary. The error of measurement series can be defined by the standard deviation. The median of standard deviation for measurements for the horizontal arrangement of the channel is $36.4 \%$ and $24.9 \%$ for the vertical.

Table 1. Absolute errors of the measured and calculated quantities.

\begin{tabular}{|c|c|}
\hline Parameter & Error \\
\hline Pressure $(p)$ & $0.01325 \mathrm{bar}$ \\
\hline Temperature $(T)$ & $0.55 \mathrm{~K}$ \\
\hline Pressure drop $(\Delta p)$ & $1.725 \mathrm{~Pa}$ \\
\hline Voltage $(U)$ & $0.006 \mathrm{~V}$ \\
\hline Amperage $(I)$ & $0.006 \mathrm{~A}$ \\
\hline Volumetric flow rate $(V)$ & $1.04 \mathrm{E}-9 \mathrm{~m}^{3} \mathrm{~s}^{-1}$ \\
\hline Heating power $(N)$ & $0.072 \mathrm{~W}^{\prime}$ \\
\hline
\end{tabular}

\section{Mathematical model}

Due to the measurement module design, figure 3 , this mathematical model concerns heat transfer in only two regions: region I $\left(\Omega_{I}\right)$, where in the section with a length of $H_{I}=93 \mathrm{~mm}$ there is the heater heating the liquid flowing into the minichannel and region III $\left(\Omega_{I I I}\right)$ with adiabatic flow; this region concerns the $77 \mathrm{~mm}$ long end section of the measurement module.

The steady state in the test module was assumed for the mathematical model. The temperature changes in the insulating foil, heater and liquid along the minichannel width were assumed to be minor. Two dimensions were considered in this approach: dimension $x$ parallel to the flow direction and perpendicular to it dimension $y$ for the thickness of the insulating foil $\left(\delta_{f}\right)$, the heater $\left(\delta_{h}\right)$ and the depth of the minichannel $\left(\delta_{m}\right)$. Further considerations refer only to the central cross section of the measurement module. The parameters referring to the foil, heater and liquid were annotated by subscripts: $f$ for the insulating foil, $h$ for the heater and $L$ for the liquid.

The temperature of the insulating foil $T_{f}$ in $\Omega_{f, I}=\left\{(x, y) \in R^{2}: 0<x<H_{I}, \quad 0<y<\delta_{f}\right\}$

was assumed to fulfill Laplace's equation

$$
L T_{f}=0
$$

where $L=\frac{\partial^{2}}{\partial x^{2}}+\frac{\partial^{2}}{\partial y^{2}}$.

For equation (1) the following boundary conditions were adopted

$$
\begin{aligned}
& T_{f}\left(x_{k}, 0\right)=T_{k} \text { for } k=1,2, \ldots, K_{I} \\
& \frac{\partial T_{f}}{\partial y}=0 \text { for } y=0,0 \leq x \leq H_{I} \\
& \frac{\partial T_{f}}{\partial x}=0 \text { for } 0 \leq y \leq \delta_{f}, x=0
\end{aligned}
$$

where $T_{k}$ denotes discrete foil external temperature measurement made with the IR camera at $K_{I}$ measurement points $\left(x_{k}, 0\right)$.

The temperature of the heater, $T_{h}$, in $\Omega_{h, I}=\left\{(x, y) \in R^{2}: 0<x<H_{I}, \quad \delta_{f}<y<\delta_{f}+\delta_{h}\right\}$ satisfies the Poisson equation

$$
L T_{h}=-\frac{q_{V}}{\lambda_{h}}=-\frac{I \Delta U}{A_{h} \lambda_{h}}
$$

where $q_{V}$ denotes the volumetric flow rate supplied to the heating foil, $\lambda_{h}$ is the heater thermal conductivity and $A_{h}$ is the surface area of the heater.

The following boundary conditions were adopted for equation (5)

$$
\begin{aligned}
& T_{f}\left(x, \delta_{f}\right)=T_{h}\left(x, \delta_{f}\right) \text { for } 0 \leq x \leq H_{\mathrm{I}} \\
& \lambda_{f} \frac{\partial T_{f}}{\partial y}=\lambda_{h} \frac{\partial T_{h}}{\partial y} \text { for } y=\delta_{h}, 0 \leq x \leq H_{\mathrm{I}}
\end{aligned}
$$

The distribution of ethanol temperature depends on the flow type. Different ways of temperature computation are used when the single-phase convection region predominates in the minichannel and ends with boiling incipience, and when two-phase flow occurs with developed bubbly or bubbly-slug boiling. The first of these flow types is still defined as single-phase flow, whereas the latter is just the two-phase flow. The assumptions for both flow types were as follows: (a) the flow of the liquid in the minichannel is laminar $(\operatorname{Re}<2100)$ and stationary with constant mass flux, 
(b) the velocity of the liquid in the minichannel has only one non-zero component $w(y)$ parallel to the heating surface, fulfilling the condition resulting from the momentum equation

$$
-\frac{d p}{d x}+\mu_{L} \frac{\partial^{2} w}{\partial y^{2}}=0
$$

where $\mu_{L}$ is the dynamic viscosity of the liquid. (c) the temperature of the liquid at the inlet $\left(T_{i n}\right)$ and outlet $\left(T_{\text {out }}\right)$ of the minichannel is known.

For the single-phase flow with boiling incipience, the liquid temperature was taken to change linearly in the minichannel: from the inlet temperature to the outlet temperature. Both of these temperatures are known from the measurements. For the two-phase flow, when limiting the considerations to the liquid phase, the temperature of the liquid in region

$\Omega_{L, I}=\left\{(x, y) \in R^{2}: 0<x<H_{I}, \delta_{f}+\delta_{h}<y<\delta_{f}+\delta_{h}+\delta_{m}\right\}$ was assumed to fulfill the energy equation

$$
\lambda_{L} L T_{L}=w(y) c_{p} \rho_{L} \frac{\partial T_{L}}{\partial x}-\mu_{L} \Phi-w(y) \frac{d p}{d x}
$$

where $\frac{d p}{d x} \approx \frac{p_{\text {out }}-p_{\text {in }}}{H_{I I I}}=\frac{\Delta p}{H_{I I I}}, H_{I I I}=193 \mathrm{~mm}$ is the minichannel length (figure 3) and $\Phi=\frac{q_{V}}{\mu_{L}}=\left(\frac{d w}{d y}\right)^{2}$ is the Rayleigh dissipation function.

For equation (9) additional boundary conditions were adopted:

(d) the two-phase mixture resulting from the flow in the minichannel is characterized by void fraction $\varphi$. The heat flux generated in the heating foil is transferred to the liquid phase in the proportion dependent on the void fraction, i.e.

$$
\lambda_{L} \frac{\partial T_{L}}{\partial y}=(1-\varphi(x)) \lambda_{h} \frac{\partial T_{h}}{\partial y}
$$

(e) the liquid temperature for $x=H_{\mathrm{I}}$ satisfies the condition

$$
T_{L}\left(H_{I}\right)=T_{\text {sat }}\left(H_{I}\right)
$$

where $T_{s a t}(x)$ is the saturation temperature dependent on linearly variable pressure.

(f) the liquid temperature at the contact with the heater satisfies the condition

$$
T_{L}=\left\{\begin{array}{l}
T_{h}, \text { for } T_{h}<T_{\text {sat }} \\
T_{\text {sat }}, \text { for } T_{h} \geq T_{\text {sat }}
\end{array}\right.
$$

The known distributions of the heater and liquid temperatures allow determining the heat transfer coefficient $\alpha(x)$ from the Robin boundary condition

$$
\alpha(x)=\frac{-\lambda_{h} \frac{\partial T_{h}}{\partial y}\left(x, \delta_{h}+\delta_{f}\right)}{T_{h}\left(x, \delta_{h}+\delta_{f}\right)-T_{L, 0}(x)}
$$

In (13), the reference temperature $T_{L, 0}$ is computed from the depending on the flow type:

- for single-phase flows

$$
T_{L, 0}(x)=T_{\text {in }}+\frac{T_{\text {out }}-T_{\text {in }}}{H_{I I I}} x
$$

- for two-phase flows

$$
T_{L, 0}(x)=\frac{1}{0.5 \delta_{m}} \int_{\delta_{f}+\delta_{r}}^{\delta_{f+\delta_{r}+0.5 \delta_{m}}} T_{L}(x, y) d y
$$

In region III in the cross-section of the measurement module, figure 3 , there is only the insulating foil and the minichannel with the ethanol. The foil temperature in $\Omega_{f, I I I}=\left\{(x, y) \in R^{2}: H_{I I}<x<H_{I I I}, \quad 0<y<\delta_{f}\right\} \quad$ was assumed to satisfy equation (1) with boundary conditions

$$
\begin{aligned}
& T_{f}\left(x_{k}, 0\right)=T_{k} \text { for } k=1,2, \ldots, K_{I I I} \\
& \frac{\partial T_{f}}{\partial y}=0 \text { for } y=0, H_{I I}<x<H_{I I I}
\end{aligned}
$$

where $H_{I I}=116 \mathrm{~mm}$ and $T_{k}$ are discrete temperature measurements made at $K_{I I I}$ measurement points.

The ethanol temperature distribution is computed in $\Omega_{L, I I I}=\left\{(x, y) \in R^{2}: H_{I I}<x<H_{I I I}, \quad \delta_{f}<y<\delta_{f}+\delta_{h}+\delta_{m}\right\}$ similarly as in the region $\Omega_{L, I}$. In the case of the twophase flow, only boundary conditions are modified: conditions (d) and (f) do not occur, and condition (e) is subject to change, i.e. for $x=H_{I I}$, the new condition (e') has the form

$$
T_{L}\left(H_{I I}\right)=T_{\text {sat }}\left(H_{I I}\right)
$$

\section{Trefftz method}

Equations (1), (5), (9) with an adequate set of boundary conditions comprise a system of three subsequent (in region $\Omega_{I}$ ) or two subsequent (in region $\Omega_{I I I}$ ) inverse heat conduction problems. The approximate solutions to these equations were found using the Trefftz method.

Two sets of Trefftz functions were used in the calculations. To determine the approximate solution to equations (1) and (5), harmonic polynomials $u_{n, 0}(x, y)$ were used, analogously as in $[5,6]$, defined by the formula

$$
u_{n, 0}(x, y)= \begin{cases}\frac{1}{\left(\frac{n}{2}\right) !} \operatorname{Re}(x+i y)^{\frac{n}{2}} & \text { for } n=0,2,4, \ldots \\ \frac{1}{\left(\frac{n+1}{2}\right) !} \operatorname{Im}(x+i y)^{\frac{n+1}{2}} & \text { for } n=1,3,5, \ldots\end{cases}
$$


where $i$ is the imaginary unit.

In each region, $\Omega_{I}$ and $\Omega_{I I I}$ the insulating foil temperature $T_{f}$ is first determined, approximated with a linear combination of harmonic polynomials, $[5,6]$

$$
T_{f}(x, y)=\sum_{n=0}^{N_{f}} a_{n} u_{n}(x, y)
$$

Coefficients of the linear combination (20) are determined in the way analogous to that in $[5,6]$, by minimizing the functional that describes the mean square error with which the approximate $T_{f}$ satisfies boundary conditions (2) - (4) (in region $\Omega_{I}$ ) or (16), (17) (in region $\left.\Omega_{I I I}\right)$. Analogous procedure is used to determine the approximate temperature of the heater, $T_{h}$, in region $\Omega_{I}$. In $[7,8]$ the Trefftz functions (19) were used for solving nonlinear direct and inverse heat transfer problems.

Trefftz functions $\theta_{n}(x, y)$ for the energy equation in the form

$$
\lambda_{L} L T_{L}=w(y) c_{p} \rho_{L} \frac{\partial T_{L}}{\partial x}
$$

are used to find the approximate temperature of ethanol.

As in [9], the solution to equation (9) is a sum of the linear combination of functions $\theta_{n}(x, y)$ and the particular solution to equation (9). The fashion of determining the coefficients of the linear combination has been described in detail in [9]. In [9], Trefftz functions $\theta_{n}(x, y)$ were determined using the expansion of the solution to equation (21) into the Taylor series. Also, several first functions $\theta_{n}(x, y)$ for the parabolic velocity profile $w(y)$ were presented. It is easy to prove that the $n$-th function $\theta_{n}(x, y)$ is the sum of the harmonic polynomial $u_{n, 0}(x, y)$ and the polynomials depending on the form of the velocity profile $w(y)$, i.e.,

$$
\theta_{n}(x, y)=u_{n, 0}(x, y)+\sum_{i=1}^{m} u_{n, i}(x, y)
$$

Functions $u_{n, i}(x, y)$ for $i=1,2, \ldots, m=\left[\frac{n}{2}\right]$, where $[\cdot]$ denotes the greatest integer function, satisfy the relation

$$
u_{n, i}(x, y)=\frac{1}{a} L^{-1}\left[w(y) \frac{\partial u_{n, i-1}}{\partial x}\right]
$$

In (23), the inverse operator $L^{-1}$ for monomials $\frac{x^{n} y^{k}}{n ! k !}$, where $n, k=0,1,2, \ldots$, is represented by, [10]

$$
L^{-1}\left\{\frac{x^{n} y^{k}}{n ! k !}\right\}=\sum_{j=0}^{m}(-1)^{j} \frac{x^{n-2 j} y^{k+2 j+2}}{(n-2 j) !(k+2 j+2) !}
$$

Determined using the Trefftz method, temperature approximations $T_{f}, T_{h}, T_{L}$ are the continuous functions that satisfy equations (1), (5) and (9) exactly, and fulfill the boundary conditions adopted for these equations approximately.

\section{Results}

The results of the calculations performed for the experimental data presented in figures 8 and 9 are shown below. For single-phase flows, the measurements from the IR camera of the foil surface for the region $\Omega_{I}$ are shown in figure $8 \mathrm{a}$. First, the approximate $2 \mathrm{D}$ foil temperature distribution was determined using the Trefftz method. Then the same procedure was conducted for the heater. Figure $8 \mathrm{~b}$ and figure $8 \mathrm{c}$ show good agreement in satisfying conditions (6) and (7) by approximated temperatures $T_{f}$ and $T_{h}$. The largest differences occur between the measurements and the temperature of the insulating foil, figure 12 a, said differences reaching maximum of $3.9 \mathrm{~K}$ (1.8 $\mathrm{K}$ on average).

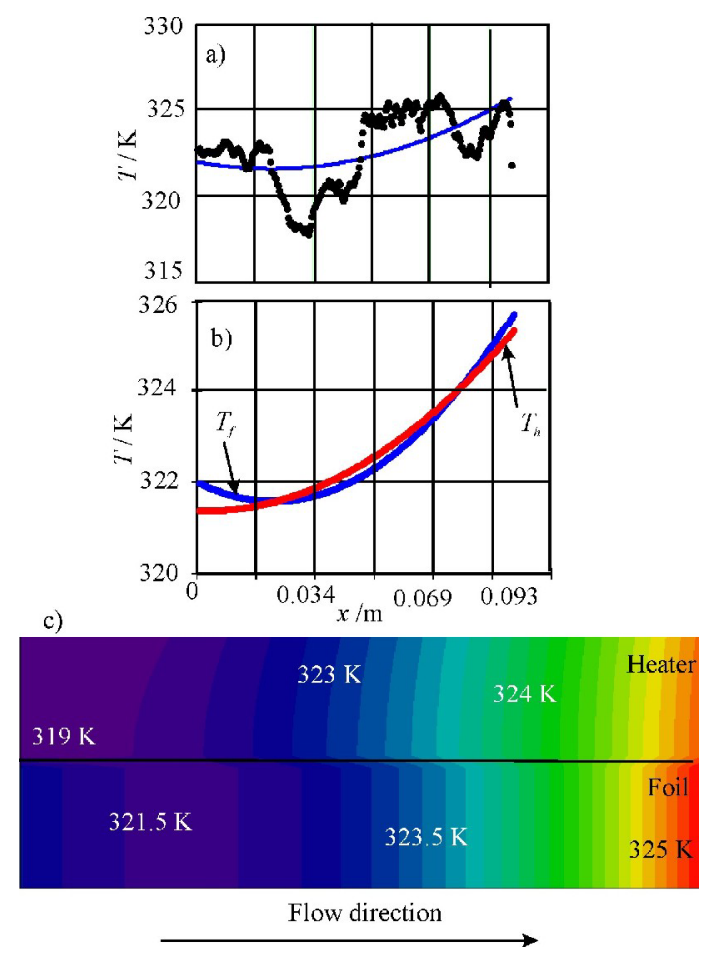

Figure 8. For the single-phase flow: a) foil temperature obtained from the IR camera (dotted line) and that calculated using the Trefftz method (solid line), b) foil $\left(T_{f}\right)$ and heater $\left(T_{h}\right)$ temperature at the foil-heater contact, c) 2D temperature distribution for the insulating foil and the heater obtained using the Trefftz method in region $\Omega_{I}$; experimental data: mean velocity $0.022 \mathrm{~m} \mathrm{~s}^{-1}$, mass flux $134 \mathrm{~kg} \mathrm{~m}^{-2} \mathrm{~s}^{-1}$, inlet pressure $6.83 \mathrm{kPa}$, heat flux: $23.71 \mathrm{~kW} \mathrm{~m}^{-2}$.

For two-phase flows, the calculation in region $\Omega_{I}$ were performed at a small $(\sim 8 \%)$, medium $(\sim 60 \%)$, and large $(\sim 80 \%)$, volume of void fraction, figure 9 . The void fractions experimentally determined at selected points were approximated with a cubic function, figure 9 . The foil temperature distribution obtained using the IR camera is analogous to that shown in figure 8 a (dotted line). 


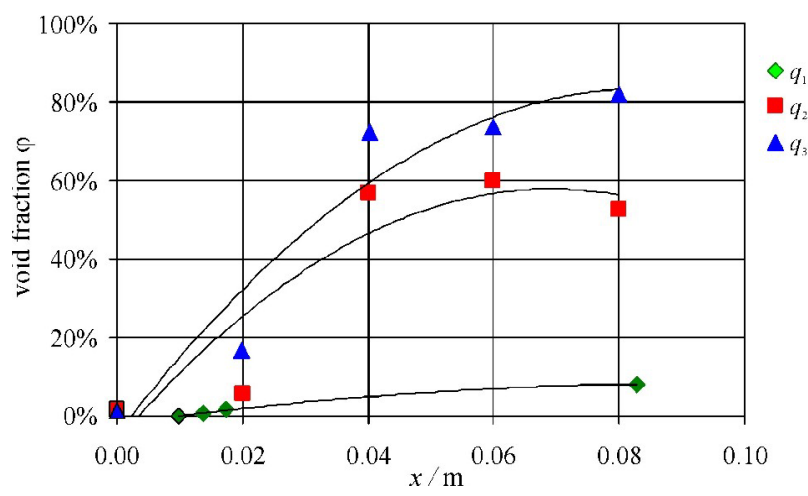

Figure 9. Experimentally determined void fractions approximated using a cubic function when: $q_{1}=73.66 \mathrm{~kW} \mathrm{~m}^{-2}$, (the coefficient of determination $R^{2}=0.9$ ), $q_{2}=122.96 \mathrm{~kW} \mathrm{~m}^{-2}$ $\left(R^{2}=0.82\right), q_{3}=152.04 \mathrm{~kW} \mathrm{~m}^{-2}\left(R^{2}=1\right)$; experimental data: mean velocity $0.022 \mathrm{~m} \mathrm{~s}^{-1}$, mass flux $134 \mathrm{~kg} \mathrm{~m}^{-2} \mathrm{~s}^{-1}$, inlet pressure $6.83 \mathrm{kPa}$.

While determining the approximate temperature distributions in the measurement module using the Trefftz method, first the insulating foil temperature distribution was determined, then the temperature distribution of the heater was found and finally that of the ethanol. This procedure leads to the solution of three sequential inverse heat conduction problems in region $\Omega_{I}$. The number of Trefftz functions was selected so that the calculated approximations were polynomials of the same degree. Figure 10 summarizes examples of 2D diagrams of approximated temperature distributions for the heater and ethanol determined in region $\Omega_{I}$.

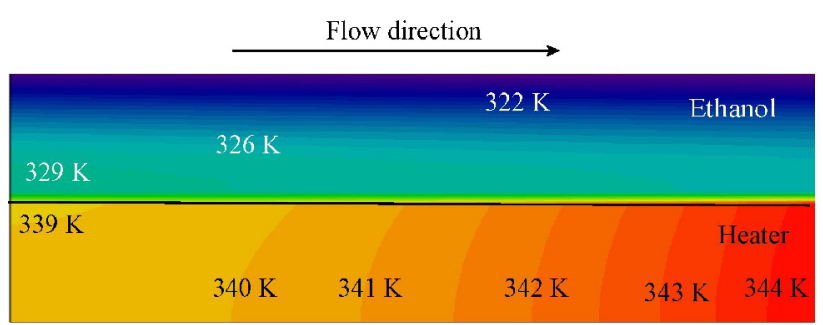

Figure 10. 2D temperature distributions of the ethanol and the heater determined using the Trefftz method; experimental data: heat flux $q_{1}=73.66 \mathrm{~kW} \mathrm{~m}^{-2}$, mean velocity $0.022 \mathrm{~m} \mathrm{~s}^{-1}$, mass flux $134 \mathrm{~kg} \mathrm{~m}^{-2} \mathrm{~s}^{-1}$ inlet pressure $6.83 \mathrm{kPa}$.

The 2D temperature distribution for the ethanol in $\Omega_{I}$ and in $\Omega_{I I I}$ is shown in figure 11. Figure 11 shows, especially visible in $\Omega_{I}$, the influence of the parabolic velocity profile on the liquid temperature distribution.

Known temperature distribution of the ethanol and the heater allows defining the heat transfer coefficient on the basis of boundary condition (13). Figure 12 shows heat transfer coefficients computed in $\Omega_{I}$ for the considered void fractions dependent on the heat fluxes supplied to the heater, figure 9 .

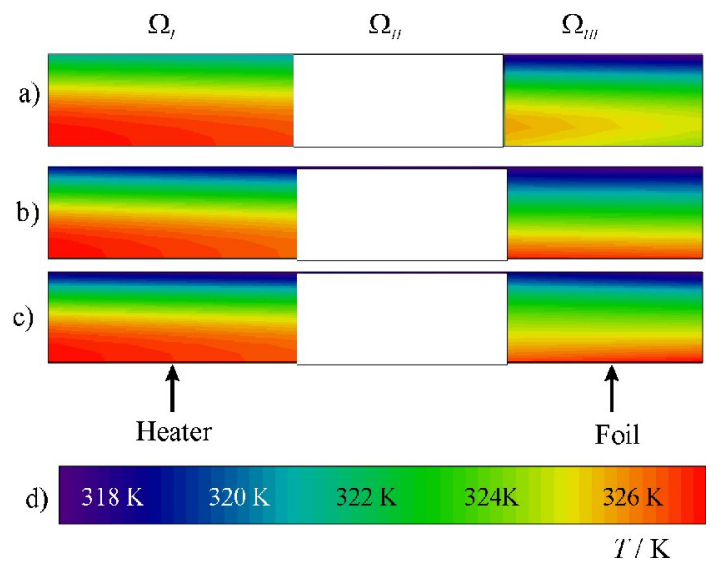

Figure 11. 2D ethanol temperature distributions for: a) $q_{1}=73.66 \mathrm{~kW} \mathrm{~m}^{-2}$, b) $q_{2}=122.96 \mathrm{~kW} \mathrm{~m}^{-2}$, c) $q_{3}=152.04 \mathrm{~kW} \mathrm{~m}^{-2}$

d) scale; experimental data as in figure 10 .

For small void fractions, during the flow of subheated liquid in the flow axis (few vapor bubbles appear only on the heater wall), the heat transfer coefficient decreases (figure 12 for $q_{1}$ ). Increasing the heat flux supplied to the heater leads to the development of boiling in the ethanol and the increase in the heat transfer coefficient value, (figure 12 for $q_{2}$ and $q_{3}$ ).

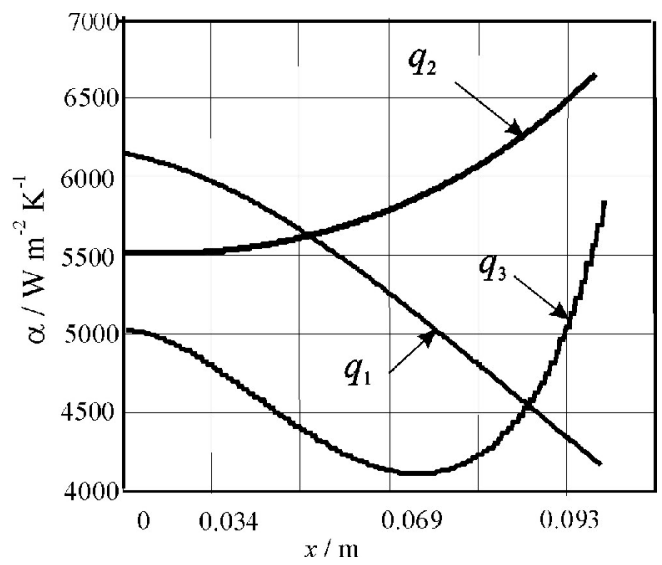

Figure 12. Heat transfer coefficients for $q_{1}=73.66 \mathrm{~kW} \mathrm{~m}^{-2}$, $q_{2}=122.96 \mathrm{~kW} \mathrm{~m}^{-2}, q_{3}=152.04 \mathrm{~kW} \mathrm{~m}^{-2}$; experimental data as in figure 10 .

\section{Conclusions}

The paper describes the experiments that refer to flow boiling of ethanol in minichannels. The adopted heat and flow parameters (pressure and temperature at the minichannel inlet, mass flux, heat flux supplied to the heater) as well as the measurements of temperature, pressure and void fraction obtained from the experiments were the sources of data for further simulation calculations. The images from a fast video camera allowed determining void fractions in the minichannel. Thermograms of the heater surface and of the adiabatic part of the minichannel allowed obtaining temperature profiles along the minichannel length. The read and calculated parameters met the expected dependencies (especially the void fraction as a function of the 
volumetric flow rate and heat flux) and were used to solve inverse heat conduction problems.

The paper proposes a simple mathematical model to describe stationary heat transfer in the measurement module elements and in the minichannel. Single- and two-phase flows were considered in the model. The model was formulated so as to limit to minimum the occurrence of experimentally determined constants - here these are the external temperature measurements of the insulating surface and the void fraction. In the model, the calculation procedure of the temperature of the ethanol flowing through the minichannel is coupled with the process of determining temperature distributions in the elements of the measurement module containing the minichannel (including the heater). Known temperature distributions of the heater and ethanol allow defining local heat transfer coefficients at the heater/ethanol interface. The analysis of the results indicates that the proposed Trefftz method is a highly accurate and stable tool for solving inverse heat conduction problems leading to the searched function and its gradient. It is worth noting that in the instances discussed above a maximum of three subsequent inverse problems were solved.

\section{References}

1. R. Kaniowski, M.E. Poniewski, Arch. Therm. 34, 1-19 (2013)

2. S. Witczak, Flow boiling of natural refrigerants inside conventional size channel and minichannels (in Polish), Opole University of Technology (2013)

3. M. Grabowski, M. Poniewski, S. Alabrudziński, K.Płaczkowski, App. Mech. Mater. (to be published)

4. K. Płaczkowski, M. Poniewski, M. Grabowski, S.Alabrudziński, App. Mech. Mater.(to be published)

5. M. Piasecka, S. Hożejowska, M.E. Poniewski, Int. J. Heat Fluid Flow 25, 159-172 (2004)

6. S. Hozejowska, M. Piasecka, M.E. Poniewski, Int. J. Therm. Sci. 48, 1049-1059 (2009)

7. K. Grysa, A. Maciag, A. Pawińska A., Int. J. Heat Mass Transf. 55, 7336-7340 (2012)

8. K. Grysa, A. Maciag, APCOM\&ISCM (2013) Singapore

9. S. Hożejowska, R. Kaniowski, M.E. Poniewski, Int. J. Numer. Methods Heat \& Fluid Flow 24, 811-824 (2014)

10. M. Sokała, M.J. Ciałkowski, TRECCOP'04, 251-259 (2009) 